\title{
Propostas metodológicas de ensino-aprendizagem utilizando a linguagem cartográfica no ensino fundamental II: contribuições para a Geografia
}

\begin{abstract}
RESUMO: A cartografia escolar se constitui em uma importante ferramenta para o estudo do espaço geográfico na medida em que se destina a representação dos fatos e fenômenos observados na superfície terrestre. Partindo desse entendimento, este artigo traz uma reflexão sobre a abordagem cartográfica no ensino da escola básica. Centra-se, sobretudo, na inexpressividade que a linguagem cartográfica frequentemente adquire no âmbito escolar, implicando em sérias deficiências para o ensino de Geografia. A discussão perpassa desde a origem e evolução do conhecimento cartográfico até a sua inserção na ciência geográfica. Em seguida, discuti-se a realidade da utilização cartográfica no Ensino Fundamental e por fim são apontados direcionamentos metodológicos para o uso dessa ferramenta na sala de aula.
\end{abstract}

\section{Proposed methodology of teaching-learning the language mapping using the basic education II: contributions to the Geography}

\footnotetext{
ABSTRACT: The school mapping constitutes an important tool for the study of geographical space as it is for the representation of facts and phenomena observed at the surface. Based on this understanding, this article offers a reflection on the cartographic approach in teaching elementary school. It focuses particularly on the meaninglessness that often acquires cartographic language in schools, leading to serious deficiencies in the teaching of Geography. The thread running through from the origin and evolution of cartography to its insertion in geographical science. Then, discussing the use mapping in elementary education and are appointed by order methodological directions for using this tool in the classroom.
}

\section{Camila de Freitas Câmara*}

*Licenciada em Geografia pela Universidade Federal do Ceará - UFC, Bolsista do Programa de Educação Tutorial PET/SESU.

Palavras-chave: Cartografia escolar; Ensino de Geografia; Ensino Fundamental.

Key-words: Cartography school Education; Geography; Elementary School. 


\section{Introdução}

O conhecimento cartográfico se constituiu ao longo da história como uma das principais ferramentas utilizadas pela humanidade para demarcar e expandir seus territórios. Graças as representações espaciais fornecidas pela cartografia, a ciência geográfica adquiriu 0 arsenal necessário para a compreensão da organização do espaço.

Nesse sentido, compreendendo a relevância da cartografia para o estudo do espaço geográfico, este artigo traz uma reflexão a cerca da utilização desse instrumental no ensino da escola básica, particularmente do Ensino Fundamental II que gradualmente tem reafirmado a sua importância, muito embora ainda não tenha adquirido a sua devida expressividade no âmbito escolar.

Acredita-se que o estudo cartográfico além de servir como ferramenta para o melhor entendimento dos conteúdos, viabiliza o desenvolvimento da leitura e interpretação de mapas, fundamentais para que 0 aluno compreenda a distribuição e organização dos espaços que fazem parte da realidade vivenciada. Além disso, contribui para o desenvolvimento de habilidades relativas à representação espacial.

No entanto, não é difícil encontrar pessoas que freqüentaram aulas de Geografia, durante muitos anos, e nem conseguem perceber a utilidade dos mapas porque são incapazes de compreendê-los e, por isso mesmo, a eles não atribuírem qualquer importância prática em sua vida cotidiana (RUA, 1993). Esse fato decorre de uma alfabetização cartográfica insatisfatória que associado ao seu uso indevido ou quase inexistente tem implicado em deficiências significativas no ensino de Geografia.

Baseado nas experiências vivenciadas nos estágios supervisionados, o Ensino Fundamental II tem revelado aprendizagens cartográficas insuficientes, reflexo, sobretudo, das metodologias de ensino que persistem em separar a cartografia dos conceitos geográficos. Dessa forma, neste artigo pretende-se apontar alguns direcionamentos que se fazem necessários para o fortalecimento da prática docente.

\section{Origem e evolução da Cartografia}

Desde os primórdios, os homens primitivos registravam nas cavernas desenhos de acidentes geográficos que provavelmente serviam como pontos de referência para localização ou movimentação no espaço (PEREIRA, 2007). Juntamente a essas representações surgiram os primeiros mapas, sendo considerada a primeira forma de comunicação utilizada pelo ser humano, precedendo até mesmo a escrita.

As representações ganharam formas cada vez mais precisas à medida que o ser humano adquiriu um maior conhecimento do espaço geográfico. Os sumérios, os babilônicos e os egípicios, assim como os astecas e os chineses, mesmo que de forma rudimentar, já dominavam

Geografia Ensino \& Pesquisa, v. 15, n.2, p. 153 164, maio./ago. 2011

Propostas metodológicas de ensinoaprendizagem utilizando a linguagem cartográfica no ensino fundamental II: contribuições para a Geografia as técnicas cartográficas e as utilizavam não só como orientação, mas também como instrumento de controle para o pagamento dos impostos e para fins bélicos. 0 mais antigo mapa que o mundo conhece origina-se entre os babilônios: "Trata-se de um tablete de argila cozida com a representação de duas cadeias de montanhas e, no centro delas, um rio, provavelmente 0 Eufrates" (OLIVEIRA, 1988).

Mas a grande contribuição fornecida à ciência cartográfica deve-se aos povos gregos. Devido às características geográficas favoráveis as práticas marítimas e as tradições militares os 
cosmógrafos, cartógrafos e matemáticos da Antiguidade foram impulsionados a pensar o espaço e traçar estratégias de acordo com as suas necessidades, dessa forma produziram representações cartográficas que serviram em muito para ampliar o conhecimento dos diferentes lugares.

Segundo Ribeiro e Aderson (1982, p.1):

Os primeiros fundamentos da ciência cartográfica foram lançados por Hiparco (160-120 a.c.) utilizou pela primeira vez, métodos astronômicos para a determinação de posições na superfície da Terra e deu a primeira solução ao problema relativo ao desenvolvimento da superfície da Terra sobre um plano, idealizando a projeção, cônica.

Através dos seus estudos o astrônomo grego Hiparco foi responsável pela criação do sistema de coordenadas geográficas de latitude e longitude, sendo desenvolvido a partir da aplicação de cálculos matemáticos e observação dos astros celestes.

O geógrafo, matemático e filósofo Erastótenes também se destacou na história dos povos antigos, foi responsável pelo desvendamento de grande parte do conhecimento que atualmente se tem sobre a Terra. Através da inserção de cálculos matemáticos no estudo da Geografia conseguiu descobrir de forma precisa para a época a circunferência e a inclinação do eixo da Terra. Além disso, no século III a. c., foi quem primeiro realizou as correções nos mapas em uso identificando as distorções que ocorriam ao se projetar um corpo esférico no plano (SCHÄFFER, 2005).

A mais importante contribuição no campo da cartográfia geográfica centrou-se nos estudos desenvolvidos pelo astrônomo, geógrafo e cartógrafo Claudio Ptolomeu de Alexandria (90-168 d.c.) por meio da sua obra, em oito volumes, intitulada "Geografia" lançou as bases da Geografia Matemática, na qual ensina os princípios da Cartografia Matemática, das projeções e os métodos de observação astronômica.

Na Idade Média, a cartografia vivenciou um cenário bastante desfavorável a produção de mapas, sofrendo um significativo retrocesso. Nessa época, a religiosidade cultuada na Europa contribuiu para que os mapas se tornassem menos precisos e os conhecimentos gregos fossem esquecidos.

O resgate e o aperfeiçoamento dos conhecimentos cartográficos gregos devem-se aos árabes. Conforme Ribeiro e Aderson (1982) estes calcularam o valor do comprimento do grau, construíram esferas celestes, estudaram os sistemas de projeção e organizaram tábuas de latitudes, e longitudes. Além disso, foram os povos árabes os responsáveis pela inserção da bússola na Europa, instrumento criado pelos chineses e que foi de grande importância para 0 desenvolvimento cartográfico na Idade Moderna.

O apogeu da ciência cartográfica ocorreu com as navegações marítimas, no início da Idade Moderna. O surgimento de novos instrumentos cartográficos como a bússola, a agulha magnética e o astrolábio, assim como a concepção da esfericidade da Terra, permitiu que os Europeus desbravassem pelos mares, e assim conhecessem novos espaços.

Nesse período, a obra de Ptolomeu ressurgiu fornecendo o embasamento necessário para as novas representações espaciais, sofrendo algumas adaptações e reformulações. A invenção da imprensa por Gutemberg possibilitou, por sua vez, a disseminação de uma produção cartográfica abundante e a navegação passou a ser estudada por meio de métodos mais racionais com a fundação da Escola de Sagres em Portugal (RIBEIRO \& ANDERSON, 1982).

No século $\mathrm{XVI}$, a produção cartográfica ganha um salto positivo entre os europeus, particularmente, os trabalhos dos espanhóis, portugueses, italianos e holandeses. Dentre os

Geografia Ensino \& Pesquisa, v. 15, n.2, p. 153164, maio./ago. 2011

Câmara, C. F.

ISSN 2236- 4994 
primeiros mapas modernos destacam-se os produzidos por Mercator, nome latino de Guerhard Kramer. A habilidade em construir instrumentos cartográficos permitiu que esse matemático fosse o responsável pela criação de um método novo de projeção na qual paralelos e meridianos se cruzam em ângulo reto (SCHÄFFER, 2005). Baseando-se nos estudos realizados por Ptolomeu desenhou ainda um mapa-múndi e um atlas que muito contribuíram para as expedições marítimas da época.

Os mapas tiveram o papel central na expansão e consolidação do Imperialismo europeu. Durante muitos séculos, o acesso ficou restrito aos chefes de Estado, militares e pessoas influentes servindo como armas sigilosas capazes de fornecer informações sobre os diferentes territórios.

Após a segunda Guerra Mundial a cartografia passa por um processo de renovação. 0 intenso progresso tecnológico permitiu o surgimento de novas ferramentas como 0 Geoprocessamento e o Sensoriamento Remoto. Diferentemente dos primeiros mapas que eram produzidos manualmente através de técnicas bastante simples, no pós-guerra a cartografia passou representar o espaço, por meio de fotografias aéreas, imagens de satélite, radares e informática, tornando a produção de mapas um processo mais rápido e preciso. Esses avanços vivenciados na cartografia contribuíram de forma significativa para uma maior aproximação com a ciência geográfica, já que está se dedica a compreensão da organização do espaço.

\section{Sistematização geográfica e a importância da Cartografia para a compreensão do espaço}

As contribuições deixadas pelos povos gregos ao pensamento geográfico e simultaneamente ao conhecimento cartográfico, sem dúvidas foram de grande relevância para 0 avanço desse campo do conhecimento, mas foi somente em meados do século XIX que ocorreu de fato a sistematização da Geografia enquanto ciência. Essa unificação geográfica ocorreu mediante uma série de fatores históricos que nessa época se apresentavam suficientemente maturados.

Como afirma Moraes (2005, p. 14):

Ao início do século XIX, a malha dos pressupostos históricos da sistematização da Geografia já estava suficientemente tecida. A terra estava toda conhecida. A Europa articulava um espaço de relações econômicas mundializado, o desenvolvimento do comércio punha em contato os lugares mais distantes. 0 colonizador europeu detinha informações dos pontos mais variados da superfície terrestre. As representações do globo estavam desenvolvidas e difundidas pelo uso cada vez maior dos mapas que se multiplicavam [...]

Foi nesse cenário que surgiu na Alemanha os primeiros escritos no sentido de uma Geografia sistematizada através dos trabalhos realizados por prussianos pertencentes à aristocracia, Alexandre Von Humboldt e Karl Ritter. Apesar de ambos possuírem diferentes

Geografia Ensino \& Pesquisa, v. 15, n.2, p. 153 164, maio./ago. 2011

Propostas metodológicas de ensinoaprendizagem utilizando a linguagem cartográfica no ensino fundamental II: contribuições para a Geografia concepções geográficas - Humboldt é sintético e não privilegia o homem, diferentemente de Hitter que é regional e antropocêntrico - seus estudos serviram como base para as formulações posteriores.

No final do século XIX, a sistematização geográfica é fortalecida com os trabalhos realizados pelo alemão Friedrich Ratzel e o francês Vidal de La Blache. A Geografia originada 
nesse período refletiu os preceitos almejados pelos Estados na busca de expandir e legitimar os seus territórios e o conhecimento cartográfico acumulado ao longo dos séculos se constituiu como ponto de partida para a expansão dos territórios, fornecendo o instrumental necessário para o conhecimento do espaço geográfico. Nessa época, a cartografia já pronunciava a sua importância para a ciência geográfica, particularmente, na compreensão dos diferentes espaços que naquele momento eram alvos da cobiça dos países imperialistas que os resguardavam como verdadeiros segredos de estado.

Ratzel influenciado pela realidade vivenciada na Alemanha de unificação do seu território contribuiu de forma significativa para o expansionismo alemão, pois impulsionou o processo de legitimação da dominação de determinados grupos. A partir de sua obra de maior relevância a "Antropogeografia" defende a teoria de que os grupos sociais são diretamente influenciados pelo ambiente no qual estão inseridos, sendo, portanto, objeto de estudo da Geografia a compreensão da influência que as condições naturais exercem sobre a humanidade (MORAES, 2005). Essas reflexões fornecidas pela escola alemã foram responsáveis pela disseminação de uma corrente doutrinária que passou a ser conhecida como determinismo ambiental, definida a partir da noção de que o homem é produto do meio.

Em resposta as propostas expansionistas Ratzelianas, Vidal de La Blache critica a politização da ciência geográfica e introduz propõe a neutralidade científica como forma de enfraquecer o discurso alemão. Nas suas formulações teóricas o homem aparece como um ser ativo que sofre influência do meio, porém atua sobre este, transformando-o, essa possibilidade da ação humana sobre o meio foi responsável pela origem do termo possibilismo (MORAES, 2005).

Como se pode observar o discurso geográfico permaneceu por muito tempo essencialmente atrelado aos interesses políticos e territoriais dos Estados Imperialistas, fornecendo todo o aporte teórico e instrumental capaz de justificar os interesses a que lhes eram convenientes.

A Cartografia escolar surgiu em meio a uma Geografia diretamente influenciada pela a ação do Estado que tem a sua gênese na Alemanha e em seguida na França. Desprovida do seu potencial estratégico que reinava entre os dirigentes do poder, a Geografia ensinada nas instituições escolares baseava-se em um discurso pedagógico essencialmente enciclopédico, onde os elementos do conhecimento eram enumerados sem nenhuma ligação entre os mesmos e que, portanto, não expressava nenhuma utilidade prática. 0 estudo cartográfico se restringia a seu caráter meramente ilustrativo e de localização. Buscando interpretar essa realidade Lacoste (1988) considera que no final do século XIX se apresentava duas Geografias bastante distintas: a Geografia dos estados-maiores abastecida por um conjunto de representações cartográficas e de conhecimentos referentes ao espaço e de suma importância estratégica e a Geografia dos professores que se constituiu em um verdadeiro discurso ideológico no qual objetiva mascarar a utilidade prática do conhecimento cartográfico.

Diante desse quadro, o conhecimento cartográfico ficou por muito tempo restrito a uma minoria que se utilizava do seu potencial estratégico como instrumento de poder. Estes se tratavam de dirigentes do Estado e oficiais militares que concentravam as informações fornecidas pelas mais variadas formas de representações espaciais. Por outro lado, a geografia presente nas instituições escolares disseminava um discurso meramente enciclopédico que dificilmente transmitia a real utilidade do conhecimento cartográfico.

Mais recentemente, ao abordar sobre 0 uso e a apropriação da linguagem cartográfica no ensino de Geografia, Katuta (2002), afirma ser possível delinear três fases distintas. A primeira

Geografia Ensino \& Pesquisa, v. 15, n.2, p. 153164, maio./ago. 2011

Câmara, C. F. 
está compreendida entre 1930 até a primeira metade da década de 70. Baseada no positivismo, a cartografia era utilizada apenas para auxiliar a localizar e descrever fenômenos, não possibilitava a compreensão da organização territorial da sociedade.

A situação muda no final de 1970 quando a Geografia passa por profundas modificações e exige a utilização de novos referenciais teórico-metodológicos, que se apoiaram na Geografia radical ou crítica. A preocupação em torno das questões metodológicas de entendimento da realidade contribuiu para que a linguagem cartográfica fosse deixada de lado, além disso, nessa época os cursos de professores passaram a enfatizar as questões da parte humana da Geografia em detrimento da Geografia física.

Em meados da década de 1980 se estendendo até os dias atuais a utilização cartográfica foi caracterizada pela valorização da sua linguagem como ferramenta para a construção de entendimentos dos diferentes espaços.

Delinear essas três fases distintas implica repensar o que se escuta muitas vezes sobre as experiências vivenciadas nos Estágios Supervisionados. Será que a cartografia está sendo de fato valorizada nas instituições de ensino atualmente? Partindo desse encaminhamento, compreende-se que esse processo vem ocorrendo lentamente, isso porque ainda torna-se perceptível o esquecimento dessa ferramenta no ensino de Geografia, particularmente no Ensino Fundamental.

\section{A utilização cartográfica no ensino fundamental}

O tratamento cartográfico no âmbito escolar exige que os professores, principalmente tenham conhecimento que esse processo envolve etapas criteriosas e determinantes para 0 desenvolvimento de uma aprendizagem satisfatória. De acordo com Almeida \& Passini (1991, p. 15) "o mapa é uma representação codificada de um determinado espaço real". Acredita ser um modelo de comunicação que se vale de um sistema semiótico complexo, onde a informação é transmitida por meio de uma linguagem que se utiliza de três elementos básicos: sistemas de signos, redução e projeção.

Ler as representações cartográficas não é apontar localizações, é preciso dar significado ao que está sendo identificado no papel, estabelecer relações e entrecruzamentos.

Mesmo sendo o uso de mapas o ponto central desta proposta deve-se considerar a importância de se trabalhar também com outras formas de representação do espaço como maquetes, gráficos, desenhos. Como afirma Cavalcanti (2002, p. 97) "o estudo de Geografia não se reduz ao trabalho com mapas, mas é necessário chamar a atenção para a conveniência de se estudar Geografia através, também, de mapas".

Simielli (1999) ao abordar a cartografia no ensino de geografia propõe três níveis que devem ser considerados no momento do seu uso no Ensino Fundamental são eles: localização e análise, correlação e síntese. A distribuição desses níveis ocorrem da seguinte forma: alunos de

Geografia Ensino \& Pesquisa, v. 15, n.2, p. 153 164, maio./ago. 2011

Propostas metodológicas de ensinoaprendizagem utilizando a linguagem cartográfica no ensino fundamental II: contribuições para a Geografia $1^{\circ}$ a $4^{\circ}\left(1^{\circ}\right.$ e $5^{\circ}$ ano $)$ deve ser trabalhado basicamente a alfabetização cartográfica que implica na apreensão de algumas noções como a visão oblíqua e vertical, construção da noção de legenda, proporção e escala, lateralidade/referências e orientação. Nessa etapa da vida escolar o estudo deve sempre partir do espaço próximo para os espaços cada vez distantes (como exemplo sala de aula, escola, bairro, município e estado). Porém esse direcionamento não segue uma ordem rigorosa, pois a alfabetização cartográfica pode ocorrer na $5^{\mathrm{a}}$ e $6^{\mathrm{a}}$ séries $\left(6^{\circ}\right.$ e $7^{\circ}$ anos). 
A partir da $5^{\mathrm{a}}$ a $8^{\mathrm{a}}$ série $\left(6^{\circ}\right.$ e $9^{\circ}$ anos) é possivel trabalhar com a análise, localização e correlação. De um lado como leitor crítico a partir de mapas já elaborados, onde o aluno não só localiza e analisa determinado fenômeno no mapa, mas correlacionam as outras variáveis. Por outro lado, pode-se ter como ponto de partida a elaboração de mapas, tornando os alunos os responsáveis pelos seus próprios mapas.

Seguindo esse direcionamento teórico, buscou-se apresentar propostas metodológicas de ensino - aprendizagem para se trabalhar com alunos do Ensino Fundamental II, a intenção consistiu em sugerir atividades que sejam capazes de abordar os conteúdos geográficos se utilizando da cartografia.

\section{Propostas direcionadas para a utilização cartográfica no ensino fundamental II}

Foi pensando em direcionar o trabalho dos professores do Ensino Fundamental, é que se buscou apresentar nesta parte da pesquisa sugestões de metodologias que possam ser aplicadas em sala de aula. Para que dessa forma a abordagem cartográfica passe a fazer parte das aulas de Geografia não como mero instrumento ilustrativo, mas como ferramenta fundamental para a análise do espaço geográfico.

\section{$1^{0}$ Sugestão: Estudo das diferentes paisagens.}

Baseado na teoria construtivista de Piaget Almeida \& Passini (1991) afirma que no processo de apreensão da noção de espaço, a criança necessita construir o seu próprio mapa, pois dessa forma induzirá a própria leitura. Seguindo esse pressuposto, o professor ao trabalhar com alunos do $6^{\circ}$ ano poderá aprofundar algumas noções (a visão oblíqua e vertical, construção da legenda, proporção e escala, lateralidade/referências e orientação) necessárias para 0 processo de alfabetização cartográfica iniciado no Ensino Fundamental I, mesmo tendo que repassar novos conteúdos. Como exemplo, toma-se como referência o estudo das diferentes paisagens. Para o estudo das paisagens, o professor poderá iniciar propondo aos alunos a elaboração de desenhos representando os elementos que compõem a paisagem do lugar onde vivem, onde devem ser destacados os elementos naturais e as construções humanas observados na paisagem.

Considerando que o desenvolvimento das noções espaciais se dá a partir do método indutivo, ou seja, do espaço próximo para áreas cada vez mais distantes (ALMEIDA \& PASSINI, 1991), tal atividade possibilitará que a apreensão do espaço ocorra de forma gradual, obedecendo aos níveis de desenvolvimento da criança. Somado a isso facilitará a compreensão da escala como um dos elementos básicos para a interpretação dos mapas, que por sua vez torna-se fundamental para a análise de determinado fenômeno geográfico.

A partir de uma roda de conversa em que os alunos irão expor aos seus colegas o que representaram em seus respectivos desenhos. 0 professor poderá atuar enfatizando as diferentes manifestações da natureza e a apropriação e transformação dela pela ação coletiva.

A noção de localização espacial poderá ser reforçada por meio do de atividades que desenvolvam os processos de descentralização e reversibilidade, pois segundo Almeida \& passini (1991) se constituem essenciais na caracterização do raciocínio operacional concreto. Com o apoio de um mapa do Brasil, o professor poderá sugerir que os alunos localizem determinado estado ou região em que gostariam de conhecer e pedir para pesquisarem através de jornais, revistas, cartões-postais, internet entre outras fontes, fotos ou imagens que

Geografia Ensino \& Pesquisa, v. 15, n.2, p. 153164, maio./ago. 2011

Câmara, C. F. 
representem a paisagem destes lugares escolhidos. Esse procedimento ajudará na observação e descrição das diferentes paisagens, assim como a identificação das principais semelhanças e diferenças entre estas, as variadas formas de apropriação da natureza e suas determinações nas relações de trabalho.

A análise poderá ocorrer ainda em âmbito mundial com o apoio do mapa-múndi, atlas e globos terrestres. Além da atividade de localização os alunos poderão ter como referência nos mapas os principais elementos que podem influenciar na diferenciação das paisagens.

Material didático: mapa do Brasil, mapa-múndi, globo terrestre, atlas, revistas, jornais entre outras fontes de pesquisa.

\section{$\underline{2}^{0}$ Sugestão: Compreendendo o relevo brasileiro utilizando a maquete}

Um das noções fundamentais para a compreensão das diferentes formas da superfície terrestres, temática que pertencente ao estudo geográfico, refere-se a percepção do espaço a partir de uma visão tridimensional. Para Almeida \& Passini (1991) o desenvolvimento da visão oblíqua do espaço deve ser explorada desde as séries iniciais, devendo, portanto, fazer parte do trabalho do professor. Nesse sentido, ao trabalhar o estudo do relevo brasileiro com alunos de $6^{\circ}$ e $7^{\circ}$ ano, o professor poderá iniciar explicando o que é relevo, os fatores que influenciam direta ou indiretamente na modelagem deste, bem como a forma como se distribuem pelo Brasil. Esse primeiro momento poderá ser realizado por meio de localização e análise utilizando o mapa do país.

Para tornar a aula mais dinâmica e evitar que aula se transforme em um mero momento de memorização, o professor poderá sugerir a elaboração de uma maquete, onde deverá ser representado as formas em alto relevo. Tal procedimento permitirá uma aproximação com as formas de representação tridimensional. Para o desenvolvimento dessa atividade a turma deverá se dividir em grupos, onde cada um pode ficar responsável por uma região do país.

0 professor deverá sugerir aos alunos que seja realizado o contorno do mapa do Brasil em uma folha fina, em seguida deverá ser desenhado no mesmo tipo de folha toda curva nível de menor altitude. Cada uma das curvas de nível mapeadas deverão ser desenhadas em folhas separadas. Posteriormente, cada uma destas deverão ser coladas em folhas de isopor com uma espessura razoável de pelo menos meio centímetro. Com a ajuda do professor recorte as curvas do isopor, utilizando a agulha quente. Depois devem ser coladas as curvas para que seja montado o relevo, sempre as curvas de maior altitude sobre as de menor altitude, até o topo das montanhas mais altas. Ao final, deverá ser passado a massa corrida para eliminar os degraus e depois pintar o que foi produzido. Através dessa atividade proposta será viabilizada a integração ou correlação de mapas proposta por Simielli (1999).

No final, o que foi produzido por cada equipe deverá ser agrupado formando o território brasileiro. Mediante o produto final o professor poderá abordar o conteúdo saindo de uma representação bidimensional (os mapas) para o tridimensional. Além disso, possibilita uma visão mais ampla de como se estrutura o relevo brasileiro e permite estabelecer relações com outros elementos como o clima, os solos, a hidrografia, os tipos de ocupação predominantes entre outras temáticas que estão diretamente ou indiretamente ligadas ao relevo.

Material didático: mapas do Brasil, papel vegetal, lápis, isopor, estilete, massa de modelar e aprendizagem utilizando a linguagem cartográfica no ensino fundamental II: contribuições para a Geografia cola. 
$\underline{3}^{0}$ Sugestão: A expansão do cultivo da soja pelo cerrado brasileiro.

Mais do que compreender um fenômeno isolado, o aluno deve ser treinado a correlacionar as diferentes informações para se atingir uma análise do todo. Conforme Simielli (1999) é necessário não somente localizar e analisar determinado fenômeno no mapa, mas correlacionar as outras variáveis. Dessa forma, ao tratar sobre a expansão do cultivo da soja, o professor poderá iniciar falando um pouco da expansão da produção de soja no cerrado brasileiro, trazendo uma reflexão sobre a intensa devastação desse bioma. Para tratar das causas associadas a esse problema poderá escrever no quadro o título de cinco mapas, explicando que a proposta é analisá-los e encontrar relações entre eles. Para a efetivação desta atividade os alunos deverão observar e descrever o mapa que representa a produção de soja no país. As informações obtidas devem ser registradas em tópicos, por escrito no caderno, para que posteriormente sejam socializadas com a turma.

Posteriormente, a turma deverá se dividir em quatro grupos que por sua vez receberão para cada um deles um dos outros quatro mapas. 0 professor deverá orientá-los a analisar 0 que trata da expansão da produção de soja no país com o que acabaram de receber, procurando estabelecer relações entre eles. A discussão poderá ser fortalecida com perguntas sobre a localização das áreas de maior ou menor cultivo e as características dessas áreas no segundo mapa, examinando se existe uma possível relação entre os dois temas. (por exemplo, é de se esperar que regiões que apresentam grande concentração de terras ocupadas pela produção de soja possuam pouca vegetação nativa por causa da devastação).

O professor deverá direcionar os alunos a estabelecer as possiveis relações entre o cultivo da soja no país e os prejuízos gerados ao cerrado brasileiro. Podendo ainda ser discutido a questão da concentração de terras como resultado dessa atividade econômica.

Material didático: Atlas geográficos que tratam dos biomas brasileiros e que representem a produção agrícola no país.

\section{$4^{0}$ Sugestão: Os fluxos de capitais produtivos}

O estudo dos fluxos de capitais produtivos possibilita que sejam trabalhados pelo professor os três níveis propostos por Simielli (1999) que são: localização e análise, correlação e síntese. Para explorar essa temática o professor poderá iniciar enfatizando a atuação das multinacionais nas últimas décadas, configurando espaços cada vez mais conectados por fluxos de capitais produtivos.

Após essa reflexão, os alunos serão orientados a listar na lousa o nome de cinco corporações multinacionais que atuam em diferentes ramos, em seguida se dividirão em grupos para elaborar uma tabela onde devem ser considerada a sede dessas empresas, os países em que estas apresentam filiais e os produtos que produzem.

Para viabilizar a atividade de localização, a professora poderá providenciar a cópia do mapa-múndi e fornecer a cada equipe. Os integrantes do grupo devem traçar setas com a ajuda de uma canetinha colorida indicando os pontos de atuação das empresas, e se possivel construir uma legenda com o que foi delineado sobre o mapa. Ao final, o professor poderá fixar na lousa um mapa representando a distribuição dos países desenvolvidos e subdesenvolvidos e pedir para que os alunos relacionem com as localizações demarcadas pelos alunos anteriormente. Podem ser direcionados alguns questionamentos: Há alguma relação entre a atuação das empresas multinacionais e a situação econômica dos países? Para onde são transferidos os lucros obtidos da produção?

Geografia Ensino \& Pesquisa, v. 15, n.2, p. 153164, maio./ago. 2011

Câmara, C. F. 
A síntese do fenômeno observado poderá ser trabalhada por meio de pequenos textos solicitados aos alunos, onde possam ser explicitados as observações realizadas ao longo da aula.

Material didático: cópia do mapa-múndi, canetinhas coloridas, cartolina, mapa representando os países desenvolvidos e subdesenvolvidos.

É preciso deixar claro que estas são apenas sugestões que podem direcionar o trabalho dos professores quanto a abordagem cartográfica no ensino de Geografia. Compreende-se que estas podem ser adaptadas a realidade escolar na qual serão utilizadas, inclusive ao conteúdo a ser abordado.

\section{Considerações finais}

O conhecimento cartográfico sempre fez parte da história da humanidade e surge antes mesmo da invenção da escrita. A forma com que esta vem evoluindo ao longo dos tempos por meio de novas técnicas reflete em representações espaciais cada vez mais precisas.

Mesmo se constituído como uma disciplina autônoma a cartografia se insere na ciência geográfica como uma importante ferramenta para a compreensão da organização do espaço. Atualmente, pode-se delinear contribuições maiores quando se refere ao ensino de Geografia, pois além de possibilitar a análise dos fatos e fenômenos observados na superfície terrestre, permite que sejam desenvolvidas habilidades relativas à construções cartográficas.

No entanto, a realidade que se configura em muitas instituições escolares é a inexpressividade da sua utilização nas aulas de Geografia ou mesmo 0 uso indevido desse recurso que tem implicado em aprendizagens insatisfatórias. A situação se evidencia principalmente no Ensino Fundamental II mediante as dificuldades que a maioria dos estudantes sente de demonstrar uma boa compreensão cartográfica.

Acredita-se que o fortalecimento do trabalho dos professores em sala de aula deve ocorrer por meio de metodologias de ensino - aprendizagem inovadoras, capazes de unir simultaneamente a linguagem cartográfica aos conteúdos de Geografia.

\section{Referências}

ALMEIDA, Rosângela Doin. de; PASSINI, Elza Yasuko. 0 espaço geográfico: ensino e representação. 15. Ed. São Paulo: Contexto, 1991.

CAVALCANTI, Lana. Geografia e Práticas de Ensino. Goiânia: Alternativa, 2002.

KATUTA, Ângela Massumi. A linguagem cartográfica no ensino superior e básico. In: PONTUSCHKA, Nídia Nacib; OLIVEIRA, Ariovaldo Umbelino de.( Orgs). Geografia em perspectiva. São Paulo: Contexto, 2002.

Geografia Ensino \& Pesquisa, v. 15, n.2, p. 153 164, maio./ago. 2011

Propostas metodológicas de ensinoaprendizagem utilizando a linguagem cartográfica no ensino fundamental II: contribuições para a Geografia
LACOSTE, Yves. A Geografia - isso serve, em primeiro lugar, para fazer a guerra; Tradução Maria Cecília França. Campinas: Papirus, 1988.

MORAES, Antônio Carlos Robert de. Geografia: pequena história crítica. São Paulo. Anablumme, 2005.

OLIVEIRA, Cêurio de. Curso de Cartografia Moderna. Rio de Janeiro, IBGE, Rio de Janeiro, 1988. 
PEREIRA, Maria Florice Rapouso. Mapas, memórias e mentes: espaço, tempo e conhecimento nas ações humanas. Fortaleza: Tiprogresso, 2007.

RIBEIRO, Antônio Jorge; ANDERSON, Paul S. A natureza da cartografia. In: ANDERSON, Paul S. Princípios de Cartografia Básica: volume $n^{0} 1$ (capítulos de 1 a 7) da série princípios de cartografia. In: RIBEIRO, Antônio Jorge; ANDERSON, Paul S. História da cartografia mundial e brasileira. Copyright: 1982.

RUA, João; WASZKIIAVICUS, F. A.; TANNURI, M.R.P.; NETO, H.P. Para ensinar geografia. Contribuição para o trabalho com $1^{\circ} 2^{\circ}$ graus. Rio de Janeiro: ACCESS Editora, 1993.

SCHÄFFER, Neiva Otero [ et al]. Um globo em suas mãos: práticas para a sala de aula. 2 ed. Porto Alegre: UFRGS Editora, 2005.

SIMIELLI, Maria Elena Ramos. Cartografia no ensino fundamental e médio. In: CARLOS, Ana Fani Alessandri (Org.). A Geografia na sala de aula. São Paulo: Contexto, 1999.

\section{Correspondência}

Camila Freitas Câmara - Rua Virgílio Coelho, nº 948. Aquiraz, Bairro Centro. CEP: 61700 - 000. Ceará

E-mail: kamila.defreitas@hotmail.com

Recebido em 21 de janeiro de 2011.

Revisado pelo autor em 28 de abril de 2011.

Aprovado em 13 de junho de 2011.

Geografia Ensino \& Pesquisa, v. 15, n.2, p. 153 164, maio./ago. 2011

Câmara, C. F. 